\title{
FACTORS AFFECTING MILK PRODUCTION: A CASE STUDY IN ANDHRA PRADESH
}

M. Koteswara Rao*

\begin{abstract}
India ranks first in milk production, accounting for 18.5 per cent of world production, achieving an annual output of 146.3 million tonnes during 2014-15. Production of milk depends on various factors like feeding, breeding and management of the animals. It is evident that among the non-agricultural and allied activities of agricultural sector, dairying is providing gainful self-employment and generating the incomes to the rural masses. The cross breed variety of buffaloes is being reared in large number; as a consequence substantial improvement in milk yield is recorded. To study the milk yield and the dairying aspects of households in Prakasam district of Andhra Pradesh who are rearing the cross breed buffaloes, the data and information is elicited from the households rearing cross breed cattle in the two selected mandals, namely Martur and Cumbum. To study the factors influencing milk yield, the multiple linear regression model is adopted by the method of ordinary least square.

The regression results for the total sample and also for sub-sample reveal that on an average 60 to 80 per cent of the variations in the value of milk yield per day per animal could be explained by fodder, green fodder and concentrates used per animal per day, and the age of the animal. Of these explanatory variables, fodder used per animal, green fodder used per animal per day are highly significant with positive impact and in terms of magnitude of impact on dependent variable, the concentrates used per animal per day is the highest. However, the explanatory variable, number of labour hours required per day did not show any significant impact on the dependent variable. The model fitted for various samples are valid as indicated by their respective $p$-values of the statistic.
\end{abstract}

* Chairman,BOS,Department of Economics, Acharya Nagarjuna University, Nagarjuna Nagar,Guntur,Andhra Pradesh.Email: dr_mkrao@yahoo.co.in 


\section{Introduction}

Agriculture is the most important industry in the world in terms of number of people employed. The estimated farm population, depending for livelihood on agriculture, hunting, fishing or forestry, is over 2.5 billion and makes up 42 percent of the total population. In developing countries, over 50 per cent of the population depends on agriculture. Although the proportion is decreasing as a result of rural-urban migration, the absolute numbers securing livelihoods from agricultural production are still increasing in the developing countries. The traditional occupation of agriculture and its allied activities viz., forestry, fisheries, dairy, cattle breeding and poultry are rapidly growing. Among the allied activities of agriculture, dairying has assumed greater importance in India due to its simple nature in generating additional employment and income. It has been practised as an allied activity in rural areas since time immemorial. India accounts for onesixth of cattle and half of buffalo population of the world.

The art of rearing of cows and buffaloes for milk is known as dairying. It is an important contributor to India's agricultural output. Milk production is an important rural activity in India providing supplementary employment and income to millions of rural households. Today, milk is India's largest crop in terms of its output value, surpassing even major cereals like rice and wheat.

At present India is the largest producer of milk in the world. The production of milk was estimated at 127.9 million tonnes in 2011-12 Now, 60 per cent of the rural households, 80 per cent of the rural farmers and 36 per cent of the rural landless have been pursuing dairying as their important and sustainable profession in rural India.

Milk production is a complex process and can be conceived as a function of several variables. Production of milk depends on various factors like feeding, breeding and management of animals. Apart from these, other factors like age at first calving, season of calving, advancement of lactation, number of lactations, human labour, age of the animal, value of the animal, etc., will also influence milk production. The knowledge of relative importance of resource inputs influencing milk production is essential for the dairy farmer for introducing desirable changes in his operation at the micro level. An attempt is made in this study to examine the average milk yields of buffaloes of different categories of farmers in Prakasam district. It examines the factors affecting milk production i.e., the relative importance of inputs used for milk production.

Few scholars have examined the factors that determine the milk production in India. Studies carried by Virender Singh and K.N. Raj (1998) Shantanu Kumar and Uma Sahu (2000), Surya Murthi (2001), Vijay Gorakh Patil (2010), Sambasiva Rao (1985) etc., relate to this area of research.

\section{Methodology}

Two mandals namely, Martur and Cumbum in Prakasam district of Andhra 
Pradesh are selected for the study. Martur mandal is identified as relatively developed mandal in the coastal belt of Prakasam district, while Cumbum mandal is located in the western part of the district which is relatively backward in terms of both agriculture and industry. It is identified that among the nonagricultural and allied activities of agricultural sector, dairying is providing gainful selfemployment and generating income to the rural people. It is also observed that there is a change in variety of cattle breed in the study area. The local breed/indigenous cattle are found very few in number in the district. The cross breed variety of buffaloes are being reared in large number, as a consequence substantial improvement in milk yield is recorded. Hence, it is decided to study the milk yield and dairying aspects of households in the study area, who are rearing the cross breed buffaloes.The data and information are elicited from the households rearing cross breed cattle in these two selected mandals.

For the purpose of data collection a prestructured questionnaire has been canvassed in the selected four villages from these two mandals, namely Kolalapudi and Konanki villages of Martur mandal and Kandulapuram and Ravipadu villages of Cumbum mandal. From these four villages 460 sample respondents pursuing dairying activity have been adopted based on random sampling technique. Out of 460 total sample respondents, 105 belong to Kolalapudi, while the remaining 100 belonging to Konanki, 119 and 136 respondents are from Konanki,
Kandulapuram and Ravipadu, respectively. To study the factors influencing milk yield, the multiple linear regression model is adopted by the method of ordinary least square.

\section{Specification of Variables}

Milk Yield: Due attention has been paid in collecting the data on milk yield. It is collected at four quarterly intervals for fifteen days in each quarter from 460 households. The weighted average of these 460 observations is taken by multiplying the milk yield with the corresponding market prices (The price is not constant).

Green Fodder: The common green fodders are local grass, lucerance, jowar, guinea grass, bajra, rhodes grass, sugarcane tops, etc., but in almost all the cases, local grass, pillipesara, jute is fed to the animals. Because of this, without using conversion factor (TDN Equivalent), the quantity of green fodder fed to the animals (either owned or purchased) in value terms is considered as the variable, while in the case of home produced grass, the imputed value of the grass is taken into consideration.

Dry Fodder: Dry fodder is poor in nutritional quality but it is the major item of feed. It comprises paddy straw, wheat straw, bajra, ragi straw, kad bi, lucerene hay, local grass hay, pulses plant residues and groundnut plant residues. But it is observed in the study area that paddy straw; bajra straw,jowar straw, horse gram straw and jute straw are available to feed the animals. Since all these are of the same constitution, no 
attempt is made to convert them into TDN equivalent. The quantity of the fodder fed per animal per day in value terms is used as a variable explaining milk production. In the case of home produced fodder, imputed value of the fodder is taken into account.

Concentrate Feeds: Concentrate feeds are very essential to increase milk production because animals cannot get sufficient nutrient feed through fodder in order to meet the requirements of growth and production. The common concentrate feeds are ricebran, wheat bran, rice husk, pulses husk, groundnut cake, gingelly cake, cotton seed, mustard seed, broken rice,bajra grain, maize grain,jowargrain, gold mohur and vijaya feed.

Labour Hours: Labour hours spent on tending of cattle has a considerable impact on milk production. It is already mentioned that feeding and management are the fundamental inputs to raise the productivity of animals. Since management is an important aspect, maintenance of animals needs more amount of labour, both family and hired. This variable includes time spent on bringing fodder from the field, chaffing, feeding the animals, milking the animal, cleaning the cattle shed, etc., whenever the use of labour is on an aggregate basis. It is apportioned to different animals on the basis of the quality fed to them.

Age of Animal: Age of an animal has a significant impact on milk production. It is a well-known fact that as the age of a particular animal increases, the milk yield increases in every successive lactation up to a particular age, then starts declining in the milkyield.

\section{Determinants of Milk Yield}

The Model considered for identifying the determinants of milk yield can be expressed as follows:

$Y=f\left(X_{1}, X_{2}, X_{3}, X_{4}, X_{5}\right)$

where

$\mathrm{Y} \quad=$ Milk yield per day per animal(₹)

$\mathrm{X}_{1} \quad=$ Fodder used per animal per day (in ₹)

$\mathrm{X}_{2}=$ Green fodder used per animal per day (in ₹)

$\mathrm{X}_{3}=$ Concentrate used per animal per day (in ₹)

X4 = Number of labour hours required per day

$X_{5} \quad=$ Age of animal (in years)

The corresponding Multiple Linear Regression Model to be estimated is specified as:

$$
Y=a ́+\hat{a}_{1} X_{1}+\hat{a}_{2} X_{2}+\hat{a}_{3} X_{3}+\hat{a}_{4} X_{4}+\hat{a}_{5} X_{5}+\stackrel{\circ}{a}
$$

Where á is the intercept and $\hat{\mathbf{a}}_{1}, \hat{\mathbf{a}}_{2^{\prime}}, \hat{\mathbf{a}}_{3^{\prime}}$ $\hat{\mathbf{a}}_{4^{\prime}} \hat{\mathbf{a}}_{5}$ are the regression coefficients to be estimated and å is the error term.

Primary data were collected from four villages, viz., Kandulapuram, Kolalapudi, Konanki and Ravipadu from 460 randomly selected individual households using a structured questionnaire. 
The Multiple Linear Regression Model, as specified above, is estimated by the method of Ordinary Least Squares for the entire sample and also for four sub-samples of individual villages. As there is a possibility of multicollinearity problem, the correlation matrix of independent variables was calculated (Table 1) and it reveals that none of the independent variables have significant correlation between them thus validating, OLS estimation of the impact of each independent variable on the dependent variable. But on inspection of OLS residuals graphically and by White's test, it is found that the heteroscedasticity problem is present in the OLS regression. Therefore, OLS procedure with correction for heteroscedasticity has been chosen to estimate the specified model. The regression results are tabulated below and the inferences drawn are discussed subsequently.

Table 1: Correlation Coefficients

\begin{tabular}{cccccc}
\hline & $\mathrm{X}_{1}$ & $\mathrm{X}_{2}$ & $\mathrm{X}_{3}$ & $\mathrm{X}_{4}$ & $\mathrm{X}_{5}$ \\
\hline $\mathrm{X}_{1}$ & 1.0000 & 0.0660 & 0.1719 & -0.0401 & 0.1153 \\
$\mathrm{X}_{2}$ & & 1.0000 & 0.1975 & 0.1165 & 0.0708 \\
$\mathrm{X}_{3}$ & & & 1.0000 & -0.0820 & 0.0749 \\
$\mathrm{X}_{4}$ & & & & 1.0000 & 0.0048 \\
$\mathrm{X}_{5}$ & & & & & 1.0000 \\
\hline
\end{tabular}

Using the observations 1 - 460

Under the null hypothesis that the variables are correlated.

5 per cent critical value (two-tailed) $=0.0914$ for $n=460$.

Model - 1:

Heteroscedasticity -corrected OLS:

Table 2: Regression Coefficients

\begin{tabular}{ccccc}
\hline $\begin{array}{c}\text { Independent } \\
\text { Variables }\end{array}$ & $\begin{array}{c}\text { Coefficient } \\
\text { Error }\end{array}$ & Standard & t-ratio & p-value \\
\hline const & 144.601 & 16.21 & 8.917 & 0.000 *** \\
$X_{1}$ & 0.592 & 0.17 & 3.383 & $0.000^{* * *}$ \\
$X_{2}$ & 0.191 & 0.08 & 0.191 & $0.021^{* *}$ \\
$X_{3}$ & 0.963 & 0.22 & 0.963 & $0.000^{* * *}$ \\
$X_{4}$ & 2.400 & 1.64 & 2.400 & 0.145 \\
$X_{5}$ & 5.09 & 2.06 & 5.09 & $0.0142^{* * *}$ \\
\hline
\end{tabular}

Journal of Rural Development, Vol. 36, No. 1, January - March : 2017 
Number of observations ( $n=460$ )

Dependent variable:Y

** Indicates significant at 5 per cent level.

*** Indicates significance at 1 per cent level.

Statistics based on the weighted data:

R-squared $\quad 0.675226$ Adjusted R-squared 0.665041

$\begin{array}{llll}F(5,454) & 7.38 & \text { P-value(F) } & 0.000\end{array}$

Excluding the constant, $p$-value is highest for $\left(X^{4}\right)$

Regression results for the total sample (Model-1) show that the estimated model is able to explain about 66 per cent of the variations in the dependent variable. Except for the variable, the number of labour hours required per day $\left(X_{4}\right)$ and all the remaining independent variables have a statistically significant positive impact on the dependent variable, milk yield $(Y)$. The overall significance of the model is validated by the value of $F$ statistic. Out of all the independent variables, concentrates used per animal per day $\left(\mathrm{X}_{3}\right)$ turned out to be statistically the most significant positive impact on milk yield. In terms of magnitude, age of the animal has the highest impact on milk yield. Similarly, fodder used per animal per day $\left(X_{1}\right)$ and the green fodder used per animal per day $\left(X_{2}\right)$ have considerable positive impact on milk yield as indicated by the positive sign of the estimated coefficients. However, number of labour hours spent per day $\left(\mathrm{X}_{4}\right)$ does not have significant impact on the dependent variable. These results are in tune with the results of earlier studies.

Model - 2:

Heteroscedasticity-corrected OLS:

Table 3: Regression Coefficient of Kandulapuram

\begin{tabular}{ccccc}
\hline $\begin{array}{c}\text { Independent } \\
\text { Variables }\end{array}$ & $\begin{array}{c}\text { Coefficient } \\
\text { Error }\end{array}$ & Standard & t-ratio & p-value \\
\hline const & 81.13 & 4.14 & 19.59 & $0.000^{* * *}$ \\
$X_{1}$ & 0.14 & 0.062 & 2.38 & $0.018^{* * *}$ \\
$X_{2}$ & 0.26 & 0.055 & 4.72 & $0.000^{* * *}$ \\
$X_{3}$ & 0.41 & 0.024 & 17.20 & $0.000^{* * *}$ \\
$X_{4}$ & 1.43 & 0.44 & 3.20 & $0.001^{* * *}$ \\
$X_{5}$ & 0.45 & 0.46 & 0.97 & 0.332 \\
\hline
\end{tabular}

Journal of Rural Development, Vol. 36, No. 1, January - March : 2017 
Using sampling observations for village, Kandulapuram $(n=136)$

Dependent variable:Y

*** Indicates significance at $1 \%$ level.

Excluding the constant, $p$-value is highest for variable $\left(X_{5}\right)$.

Statistics based on the weighted data:

R-squared $\quad 0.801 \quad$ Adjusted R-squared 0.794

$\begin{array}{lll}F(5,130) & 105.11 \text { P-value(F) } & 0.000\end{array}$

Excluding the constant, $\mathrm{p}$-value is highest for variable $\left(\mathrm{X}_{5}\right)$

The model specified performed well for the data on Kandulapuram village which consists of 136 observations. The adjusted Rsquared value indicates that independent variables of the model account for about 79 per cent of the variations in the dependent variable. The overall significance of the model is validated by the value of $\mathrm{F}$ statistic. Except for the age of the animal $\left(X_{5}\right)$, all the remaining independent variables have shown statistically significant positive impact on milk yield. Among the independent variables, concentrate used per day $\left(\mathrm{X}_{3}\right)$ was statistically the most significant and in terms of magnitude of impact and number of labour hours required per day $\left(\mathrm{X}_{4}\right)$ is the dominant factor. Green fodder and other fodders used are also influencing the milk yield of animals positively.

Model - 3:

Heteroscedasticity-corrected OLS:

Table 4: Regression Coefficient of Kolalapudi

\begin{tabular}{ccccc}
\hline $\begin{array}{c}\text { Independent } \\
\text { Variables }\end{array}$ & $\begin{array}{c}\text { Coefficient } \\
\text { Error }\end{array}$ & Standard & t-ratio & p-value \\
\hline const & 81.76 & 3.96 & 20.62 & $0.008 * * *$ \\
$X_{1}$ & 0.240 & 0.09 & 2.64 & $0.009 * * *$ \\
$X_{2}$ & 0.14 & 0.03 & 4.66 & $0.000^{* * *}$ \\
$X_{3}$ & 0.287 & 0.06 & 4.27 & $0.000 * * *$ \\
$X_{4}$ & 0.630 & 0.50 & 1.23 & 0.214 \\
$X_{5}$ & 0.806 & 0.34 & 2.32 & $0.022 * *$ \\
\hline
\end{tabular}

Journal of Rural Development, Vol. 36, No. 1, January - March : 2017 
using sampling observations for village Kolalapudi $(n=105)$

Dependent variable:Y

** Indicates significant at 5 per cent level.

*** Indicates significance at 1 per cent level.

Statistics based on the weighted data:

R-squared

0.637723 Adjusted R-squared 0.619

$\mathrm{F}(5,100)$

6.23 P-value(F)

0.000

Statistics based on the original data:

Excluding the constant, $\mathrm{p}$-value is highest for variable $\left(\mathrm{X}_{1}\right)$

The model specified has a moderate fit for the data on village Kolalapudi with a sample size of 106 observations. The independent variables of the model could explain about 62 percent of variations in the milk yield of animal. Fodder used per animal $\left(X_{1}\right)$,green fodder used per animal $\left(X_{2}\right)$ and concentrate used $\left(X_{3}\right)$ have displayed statistically significant positive impact on milk yield. Like earlier results, the number of labour hours required per day $\left(X_{4}\right)$ does not have a significant impact on milk yield. The age of animal $\left(X_{5}\right)$ seems to have strong positive impact on milk yield as per the regression results. Even though the model could moderately explain the variations in the dependent variable, the overall fit of the model is quite good as indicated by the $p$-value of the F statistic.

Model - 4:

Heteroscedasticity-corrected:

Table 5: Regression Coefficients of Konanki

\begin{tabular}{ccccc}
\hline $\begin{array}{c}\text { Independent } \\
\text { Variables }\end{array}$ & $\begin{array}{c}\text { Coefficient } \\
\text { Error }\end{array}$ & Standard & t-ratio & p-value \\
\hline const & 104.93 & 4.45 & 23.54 & $0.000 * * *$ \\
$X_{1}$ & 0.18 & 0.07 & 2.47 & $0.022 * *$ \\
$X_{2}$ & 0.09 & 0.05 & 1.82 & 0.07 \\
$X_{3}$ & 0.56 & 0.15 & 3.74 & $0.000 * * *$ \\
$X_{4}$ & 0.98 & 0.74 & 1.32 & 0.189 \\
$X_{5}$ & 1.84 & 0.69 & 2.66 & $0.009 * * *$ \\
\hline
\end{tabular}

using sampling observations for village Konanki $(n=100)$

Dependent variable:Y

** Indicates significant at 5 per cent level.

*** Indicates significance at 1 per cent level. 
Statistics based on the weighted data:

\begin{tabular}{llll}
\hline R-squared & 0.604 & Adjusted R-squared 0.592 & \\
$F(5,100)$ & 5.13 & P-value $(F)$ & 0.0003
\end{tabular}

Excluding the constant, $p$-value is highest for variable $\left(X_{4}\right)$

For the village Konanki, the sample data consists of 106 observations and the model fit is ap prop riate as the F statistic is highly significant as about 60 per cent of the variations in dependent variable are captured by the independent variables. Both fodderused per day
$\left(X_{1}\right)$ and concentrates used $\left(X_{3}\right)$ have a significant positive impact on milk yield. However, green fodder $\left(\mathrm{X}_{2}\right)$ and number of labour hours required per day $\left(\mathrm{X}_{4}\right)$ do not show significant impact on milk yield. The impact of age of the animal on milkyield is quite significant even in this sample.

\section{Model - 5:}

Heteroscedasticity-corrected OLS:

Table 6: Regression Coefficients of Ravipadu

\begin{tabular}{ccccc}
\hline $\begin{array}{c}\text { Independent } \\
\text { Variables }\end{array}$ & $\begin{array}{c}\text { Coefficient } \\
\text { Error }\end{array}$ & Standard & t-ratio & p-value \\
\hline const & 204.93 & 20.97 & 9.77 & $0.000^{* * *}$ \\
$X_{1}$ & 1.54 & 0.26 & 5.82 & 0.000 *** \\
$X_{2}$ & 0.37 & 0.14 & 2.61 & $0.01^{* * *}$ \\
$X_{3}$ & 1.34 & 0.56 & 2.39 & $0.018^{* * *}$ \\
$X_{4}$ & 1.60 & 0.95 & 1.68 & 0.096 \\
$X_{5}$ & -0.83 & 1.79 & -0.46 & 0.64 \\
\hline
\end{tabular}

using observations for village Ravipadu $(n=119)$

Dependent variable:Y

*** Indicates significance at 1 per cent level.

Statistics based on the weighted data:

R-squared $\quad 0.697495$ Adjusted R-squared 0.67870

$\begin{array}{lll}F(5,109) & 9.231804 & \text { P-value (F) }\end{array}$

Excluding the constant, $p$-value is highest for variable $\left(X_{5}\right)$ 
The model fit for Ravipadu village with a smaple size of 115 observations is reasonably good with an adjusted R-squared value of about 68 per cent and highly significant $F$ statistic. For this sample also fodder $\left(X_{1}\right)$, green fodder $\left(X_{2}\right)$ and concentrate fodder used $\left(X_{3}\right)$ are the major explanatory variables for milk yield and concentrate fodder used per animal $\left(X_{3}\right)$ being the most dominant factor as indicated by the magnitude of the coefficient. However, both number of hours required per day $\left(X_{4}\right)$ and the age of animal $\left(X_{5}\right)$ do not show significant impact on milk yield.

\section{Findings of the Study}

The regression results for the total sample and also for sub-sample reveal that on an average 60 to 80 per cent of the variations in the value of milk yield per day per animal could be explained by fodder, green fodder and concentrate fodder used per animal per day, and the age of the animal.Of these explanatory variables fodder used per animal, green fodder used per animal per day are highly significant with positive impact and in terms of magnitude of impact on dependent variable, the concentrates used per animal per day is the highest. However, the explanatory variable, number of labour hours required per day did not show any significant impact on the dependent variable.The model fitted for various samples are valid as indicated by their respective $p$-values of the $\mathrm{F}$ statistic. The model predictability power can be further augmented by adding new explanatory variables but that could lead to the problem of multicollinearity.
In the light of the above findings, the following policy prescriptions are framed for development of dairy industry and its value addition in general and for the study area in particular.

(i) The scarcity of fodder throughout the country and also in the study area is noticed due to recurring droughts. The low availability of feed and fodder has become a major constraint to the growth of dairy industry. Government shall take initiative to encourage research on high-yield fo dder seeds and supply them to the rural areas. Wastelands are to be developed as fodder grounds through the participation of village panchayats.

(ii) The deficiency of protein in feed used by the farmers is an important factor responsible for the lower milk yield. It is suggested that all the farmers should include protein rich feeds in the ration of their animals. The addition of micronutrients like mineral mixture and vitamin supplements in small quantities improves dairy milk and lactation length of buffaloes.

(iii) The economic loss resulting from diseases like foot and mouth disease is enormous. Government has to initiate well-planned programmes to control these diseases, however difficult, expensive and time consuming these are. It requires concerted efforts and

Journal of Rural Development, Vol. 36, No. 1, January - March : 2017 
determination among all the players involved.

(iv) The disease forecasting, control and eradication measures will have to be taken up earnestly to provide an efficient animal healthcare. Immunisation programmes must be effectively implemented. Veterinary facilities should be extended to the dairy farmers. To attend the emergency health problems of the animals, health clinics are suggested by training the educated and enthusiastic youth.

(v) Better management of dairy animals is one of the important factors for higher milk productivity. Training on housing conditions with particular reference to heat period, conception, calving, lactation and dry period is to be imparted to the farmers. It enables them to develop the skills of management.

(vi) Public sector lending in dairy sector is low and inadequate. Attempts have to be made to create favourable economic environment for increasing capital formation in both cooperative and private dairies. Landless labourers, marginal and small farmers may be given preference in extending financial assistance, not only to purchase milch animals but also to maintain them. (vii) In order to increase the competitiveness of dairy industry, efforts should be made to reduce the cost of production. The productivity of animals can be increased by improving the breeding facilities and better healthcare management. Animal health and breeding services provision, veterinary infrastructure development and vaccinations are the responsibility of the State government. Cattle and buffalo breeding programmes have been initiated but have not had the desired impact because of a lack of coordination among the different State departments.

(viii) Lack of access to credit to expand the herd is a critical problem for farmers. There is little access to formal credit through cooperatives. Informal credit is available from private traders and agents of private companies, but the interest rate is very high. Efforts should be put on correcting these distortions and ensure availability of inputs and services, including credit.

(ix) The efforts of National Dairy Research Institute should be strengthened and extended on research and education in dairy and also in supporting the industry. 


\section{References}

1. Shantanu Kumar \& Hota (2000), "Differential Status of Dairying in India: Probable Reasons and Potential Interventions"Agricultural Situation in India, September, pp. 333-336.

2. Sambasiva Rao B (1985), "Factors Affecting Milk Production: A Study”, Indian Journal of Agricultural Economics, Vol.40, No.2, April-June.

3. Surya Murthi, S. (2001), “Dairy Farm Sector”, Kurukshetra, March pp 13-14.

4. Vijay Gorakh Patil (2010),“Marketing Analysis of Milk Production in Shirpur Jehsil of Dhule District of Maharashtra, India", Financing Agriculture, Vol. 42, No. 2, February, pp. 14-15.

5. Virender Singh and K.K. Rai (1998), "Economics of Production and Marketing of Buffalo Milk in Haryana", Indian Journal of Agriculture Economics, Vol.53, No.1, J anuary - March. 